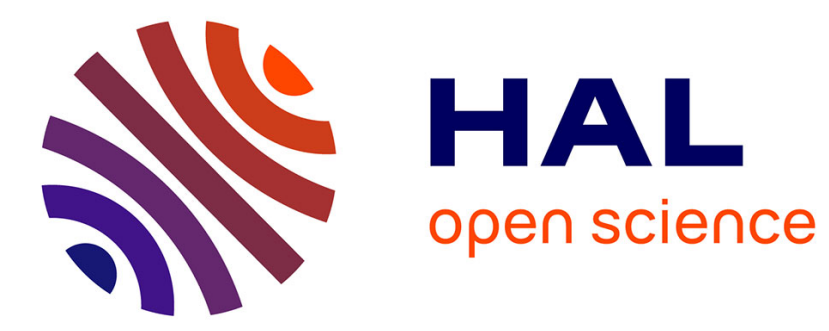

\title{
Clock Jitter Effect on Switched-Capacitor Filter Design
}

Ahmed El Oualkadi, Jean-Marie Paillot, Denis Flandre

\section{To cite this version:}

Ahmed El Oualkadi, Jean-Marie Paillot, Denis Flandre. Clock Jitter Effect on Switched-Capacitor Filter Design. Fluctuation and Noise Letters, 2006, 6 (1), 10.1142/S0219477506003112 . hal-00947411

\section{HAL Id: hal-00947411 \\ https://hal.inria.fr/hal-00947411}

Submitted on 16 Feb 2014

HAL is a multi-disciplinary open access archive for the deposit and dissemination of scientific research documents, whether they are published or not. The documents may come from teaching and research institutions in France or abroad, or from public or private research centers.
L'archive ouverte pluridisciplinaire HAL, est destinée au dépôt et à la diffusion de documents scientifiques de niveau recherche, publiés ou non, émanant des établissements d'enseignement et de recherche français ou étrangers, des laboratoires publics ou privés. 


\title{
CLOCK JITTER EFFECT ON SWITCHED-CAPACITOR FILTER DESIGN
}

\author{
A. EL OUALKADI*, J.-M. PAILLOT ${ }^{\dagger}$ and D. FLANDRE \\ Microelectronics laboratory, Electrical Engineering Department, Université Catholique de Louvain, \\ Maxwell Building, Place du Levant 3, B-1348 Louvain-la-Neuve, Belgium \\ ${ }^{\dagger}$ Laboratoire d'Automatique d'Informatique Industrielle, IUT d'Angoulême, Université de Poitiers, \\ 4, avenue de Varsovie, 16021 Angoulême Cedex, France \\ ahmed.eloualkadi@ieee.org
}

Received 12 August 2005

Revised 21 November 2005

Accepted 4 December 2005

Communicated by Charles Surya

\begin{abstract}
This paper proposes the study of clock jitter effect on high-Q switched-capacitor filter behavior. A command circuit made up by a ring voltage controlled oscillator (VCO) with XOR gates is used to generate the command signals. According to the correlation of these signals the jitter effect on the signal constellation has been studied. A good agreement between measured and simulation results has been achieved which validate our design methodology.
\end{abstract}

Keywords: Jitter; phase noise; switched-capacitor filter.

\section{Introduction}

In modern radio-communication systems, passive filters such as surface acoustic wave (SAW) are widely used. These filters present high quality factors. However, they are offchip, have high insertion losses, and are not easily tunable over a broad range of frequencies; furthermore, their manufacturing costs are prohibitive. Among the integrated filters, the switched-capacitor filters have been widely used for the design of stable, accurate and high-Q filters for operating frequencies in the megahertz range [1-4]. These filters offer interesting advantages in particular a very high selectivity associated with the possibility of adjustment of the center frequency by a clock signal. This characteristic is more significant for integrated circuits applications, for which the tuning of the center frequency by a clock signal permits either to compensate the dispersions due to the technology used, or to filter various channels with the same filter. Nevertheless, the performances of these filters are strongly related to the possibility to generate stable clock signals. For high frequency applications, time jitter becomes more important and can significantly degrade the performances of the filter [5]. Consequently, a special attention should be given to 
study the effects of time jitter in order to predict the possible degradations on the behavior of these filters.

\section{Circuit Description}

Figure 1 shows the switched-capacitor filter topology. The switches consist of NMOS transistors sequentially controlled in ON/OFF states. These transistors present a Ron resistance of $30 \Omega$ and a drain-source capacitance of $0.06 \mathrm{pF}$, to give an optimal dynamic range [6]. The input NMOS transistor, biased in the triode regime, is here introduced to implement the filter tuning.

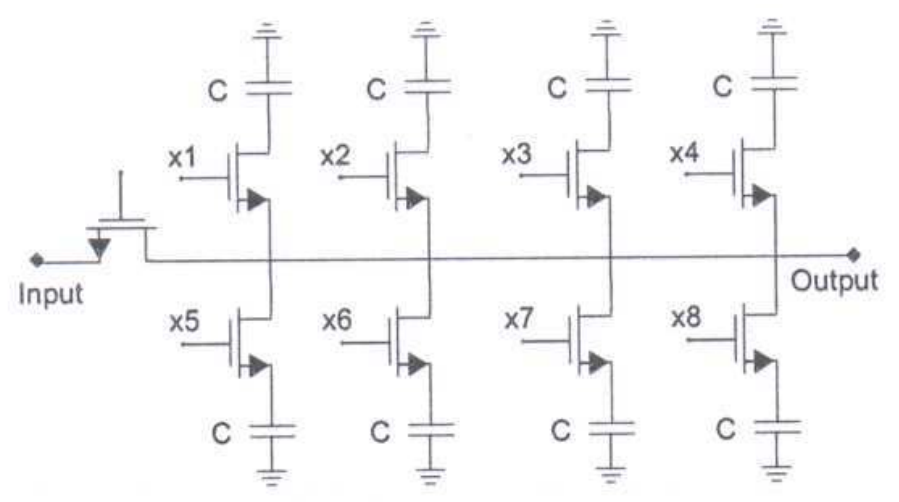

Fig. 1. Architecture of the switched-capacitor filter.

A significant limitation of this filter is related to the design of the command circuit of the switches which commonly uses low frequency shift registers. Recently a solution based on a ring voltage controlled oscillator associated with 'XOR' gates (Fig. 2) has been proposed [6]. This solution provides the possibility of tuning within a broad frequency band, sweeping different channels with high Q-factors.

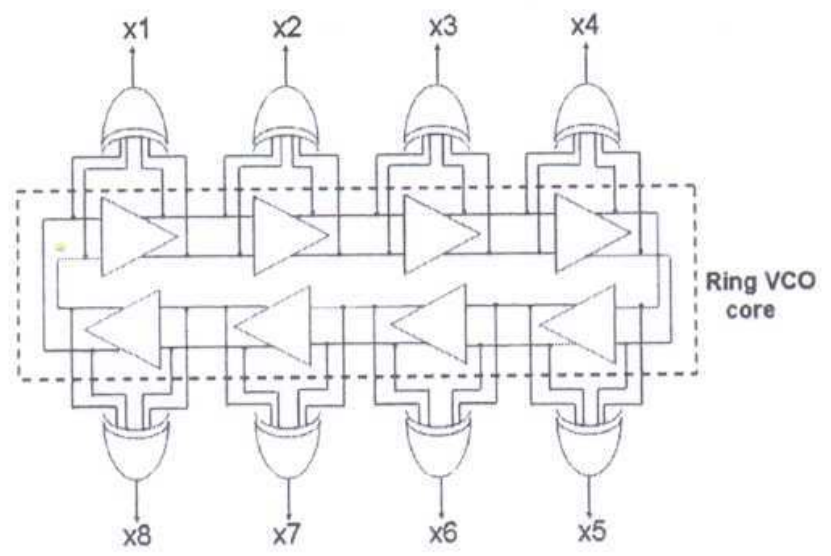

Fig. 2. Architecture of the command circuit consisting of ring VCO with 'XOR' gates.

However, if ring VCOs provide an easy integration on-chip, they are characterized by a significant unwanted phase noise compared to LC tank ones. Indeed, this undesired phase noise produces a time jitter which introduces a random variation of the instantaneous frequency. This can directly affect the command signals and consequently degrade the filter performance. 


\section{Jitter Effect on Filter Behavior}

The description details with trade-offs design of the proposed command circuit have been presented in [6]. Actually, during the ring VCO design, a special attention was given to its temporal waveform signals [7] in order to limit the jitter and hence the spectral power of phase noise at roughly $-101.46 \mathrm{dBc} / \mathrm{Hz}$ at $1-\mathrm{MHz}$ offset frequency from the carrier frequency. With this phase noise value, it is possible to calculate the jitter of the ring VCO. It appears evident that this jitter must be lower than the command impulse duration which is equal to $250 \mathrm{ps}$, with $900 \mathrm{MHz}$ center frequency and eight cells.

Since the phase noise at $1-\mathrm{MHz}$ offset from the carrier frequency is in the $1 / \mathrm{f}^{2}$ region, the jitter is generated by the conversion of a white Gaussian cyclostationary process. Thus, the cycle-to-cycle jitter $\sigma_{\mathrm{crc}}$ is defined by the following expression [7]:

$$
\sigma_{C T C}=\sqrt{\frac{1}{F}} \cdot \frac{\Delta F}{F} \cdot 10^{-L\{\Delta F\} / 20}
$$

where, $\mathrm{F}, \Delta \mathrm{F}$ and $\mathrm{L}\{\Delta \mathrm{F}\}$ are respectively the oscillation frequency, offset frequency from the carrier and noise power spectral density. Then, the calculated cycle-to-cycle jitter is equal to $0.3 \mathrm{ps}$. Such a value is insignificant compared to the impulse duration: $250 \mathrm{ps,}$ with $900 \mathrm{MHz}$ center frequency.

To predict the possible degradations which can be generated by the filter, a special attention was given to study the jitter effect when its input signal is changed to a digitally modulating signal of type $\pi / 4-D Q P S K$ (Differential Quadriphase Shift Keying) digital modulation. According to the correlation of these signals the effect on the signal constellation and consequently the EVM (Error Vector Magnitude) is quite different.

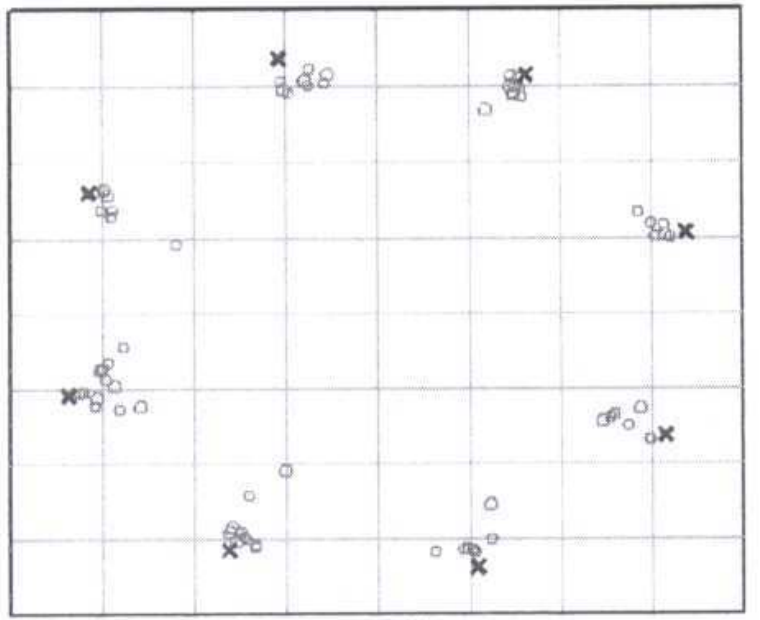

(a)

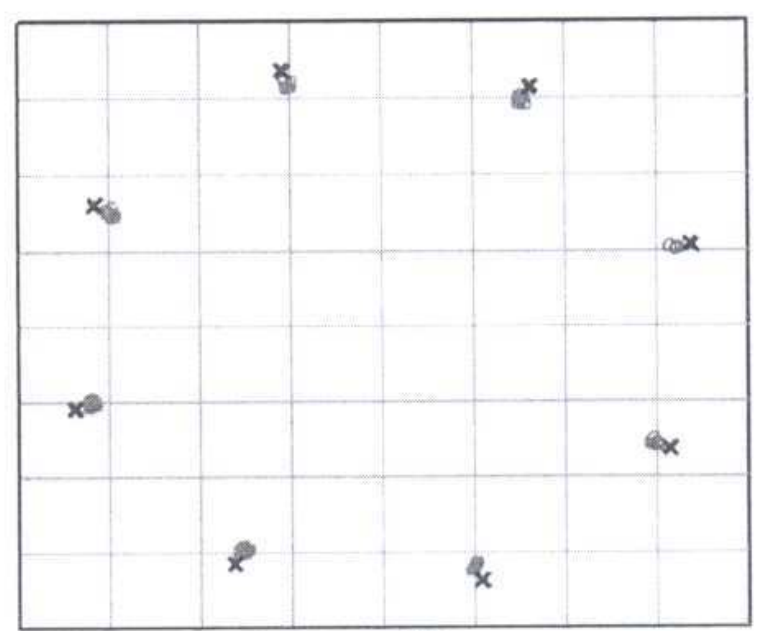

(b)

Fig. 3. Constellation diagrams of input and output circuit with, (a) uncorrelated command signals, and (b) correlated command signals.

Figure 3 shows the constellations obtained with $900 \mathrm{MHz}$ center frequency, using a $\pi / 4-D Q P S K$ digital modulation with a symbol rate equal to $24.3 \mathrm{KHz}$, by applying the same obtained phase noise value on command signals. Figure 3(a) shows the obtained output constellation compared to the ideal $\pi / 4-\mathrm{DQPSK}$ constellation. In this case, the command signals are uncorrelated by using independent switching command sources. Thus, they can overlap; this phenomenon produces a weakness of the filtering function which results in a significant degradation of the filter output constellation. This can be 
observed in the Fig. 3(a) which shows considerable shifts in the position of constellation points. However, when the command signals are generated by one single source by using the previous architecture (ring VCO), described above, the produced jitter is applied in a correlated manner on command signals without significant degradation of the output signal constellation (Fig. 3(b)). Since the simulation has been performed with identical average delays for all ring VCO cells, a fixed displacement of points can be observed in the result constellation of Fig. 3(b).

Expressed in percentage (\%), the EVM is a parameter which makes it possible to quantify the effect of the additive noise on the deformation of the transmitted signal constellation.

Table 1. Normalized EVM Values.

\begin{tabular}{|c|c|}
\hline $\begin{array}{c}\text { EVM (RMS) } \\
\text { correlated noise }\end{array}$ & $\begin{array}{c}\text { EVM (RMS) } \\
\text { uncorrelated noise }\end{array}$ \\
\hline $1.314 \%$ & $9.526 \%$ \\
\hline
\end{tabular}

Table 1 shows that the RMS value of the EVM does not exceed $2 \%$ if the command signals are correlated. While this value is close to $10 \%$ in the case of uncorrelated command impulses. From this result, it appears important to have only one source that provides all commands signals, which justifies our choice of this ring VCO to command the filter.

\section{Experimental Results}

To validate the proposed approach, a test chip composed by a switched-capacitor filter and its command circuit (ring VCO with XOR gates) was fabricated using standard $0.35 \mu \mathrm{m}$ CMOS process. Measurements based on constellation and EVM have been made.

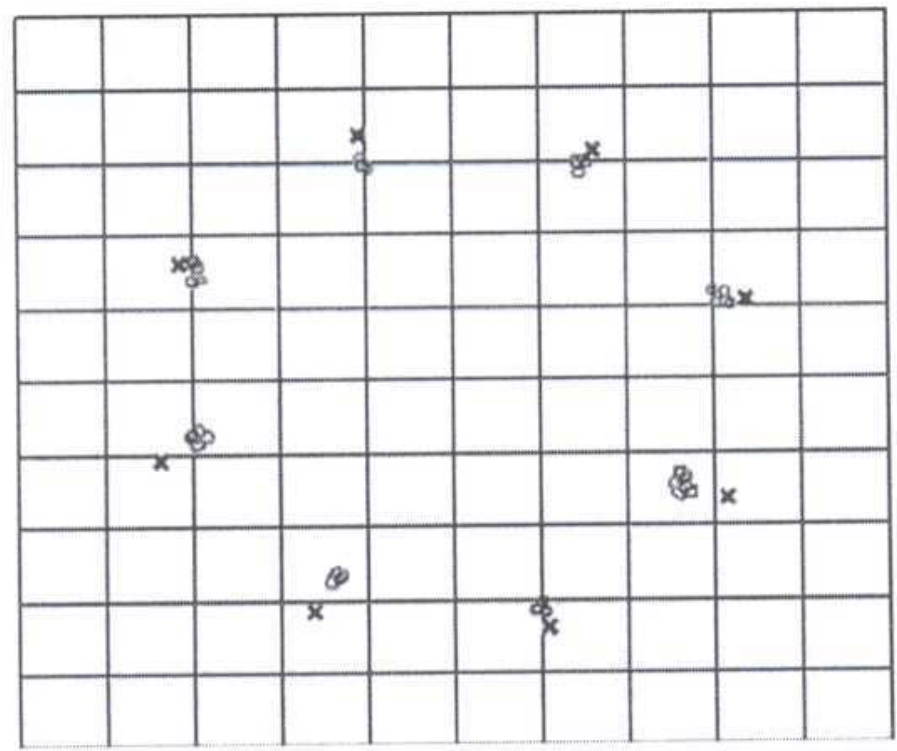

Fig. 4. Measured constellation at output filter.

Figure 4 shows the constellation obtained with $900 \mathrm{MHz}$ center frequency using a $\pi / 4$ DQPSK modulation. A slight displacement in the position points can be shown in the 
measured constellation diagram compared to simulation (Fig. 3(b)). This may be due to mismatch in the VCO delay cells and the XOR gates, since the simulation in Fig. 3(b). has been performed with identical average delays for all cells. The RMS value of the EVM is equal to $2.192 \%$ which is slightly higher than the simulation results $(1.314 \%)$.

\section{Conclusion}

The jitter effect on high-Q switched-capacitor filter has been studied. The degradations produced by this jitter have been demonstrated firstly by simulation, and after with measurements by using a $\pi / 4-D Q P S K$ digital modulation. A good agreement between measured and simulation results has been achieved which validate our choice to use the ring VCO to command the filter. This study shows the importance to take into account the jitter effect in the design of switched-capacitor circuits.

\section{References}

[1] H. Wupper, A modified N-path filter suited for practical realization, IEEE Trans. on Circuits and Systems 21 (1974) 449-456.

[2] D. Von Grûnigen, R. P. Sigg, J. Schmid, G. S. Moschytz and H. Melchior, An integrated CMOS switched-cpacitor bandpass filter based on N-path and frequency-sampling principles, IEEE J. Solid State Circuits 26 (1983) 753-761.

[3] U. Kleine, W. Brockherde, A. Fettweis, B. J. Hosticka, J. Pandel and G. Zimmer, An integrated six-path wave-SC filter, IEEE J. Solid State Circuits 20 (1985) 632-640.

[4] C. Toumazou, D. G. Haigh, S. J. Harrold, K. Steptoe, J. I. Sewell and R. Bayruns, $400 \mathrm{MHz}$ switching rate GaAs switched capacitor filter, Electron. Lett. 26 (1990) 460-461.

[5] T. H. Lee and A. Hajimiri, Oscillator phase noise a tutorial, IEEE J. Solid-State Circuits 35 (2000) 326-336.

[6] J. M. Paillot, A. El Oualkadi, H. Guegnaud and R. Allam, Switched capacitor bandpass filter tuned by ring VCO in CMOS $0.35 \mu \mathrm{m}$, Proc. IEEE RFIC-IMS Symp., Philadelphia, PA (June 2003) 119-122.

[7] A. Hajimiri and T. H. Lee, Low Noise Oscillators (Kluwer Academic Publishers, 2002). 